\title{
Design and Fabrication of Leafy Vegetable Shredding Machine
}

\author{
Agbonkhese, Kingsley A ${ }^{1}$. Omoikholo Frank ${ }^{2}$, Okojie Godwin ${ }^{3}$ and Okoekhian Leonard ${ }^{4}$ \\ Department of Mechanical Engineering Technology
}

National Institute of Construction Technology and Management (NICTM)

Uromi, Edo State, Nigeria

\begin{abstract}
With the growing world population, the need for vegetables due to its economic importance, nutritional value and viability cannot be overemphasized. In an attempt to add value to vegetables before domestically using them, a motorized electric-driven machine has been developed in order to circumvent the challenges of time consumption, contamination and injuries associated with the manual process of shredding vegetables using sharp knife. Shredding of vegetables is a process of cutting vegetables into thin slices or pieces using a sharp knife, food processor or grater. The vegetable shredding machine which works on shear principle was designed and fabricated using locally sourced materials from the opinion of new idea and tested. The performance test evaluation shows that the machine driven by a $1 \mathrm{hp}$ electric motor has an average performance cutting time of 30.2 seconds for a full hopper volume of $2319.8 \mathrm{~cm}^{3}$ which is equivalent to $78.87 \mathrm{~kg}$ of vegetables with an efficiency of $89.35 \%$ and a throughput capacity of $9400.48 \mathrm{~kg} / \mathrm{h}$. The shredding processing machine is made up of simple components that can be easily assembled. Thus, the operation and maintenance is quite easy.
\end{abstract}

Key Words: Design, Fabrication, Vegetables, Vegetable Shredding, Machine, Efficiency.

\section{INTRODUCTION}

According to Lyon (France) handbook, Vegetables are referred to as edible plants or the edible parts of plants that help in preventing micro-nutrient deficiencies and other nutritional diseases [1-2]. Vegetables are valuable nutritional sources of vitamins, minerals, and fiber [3]. The high fiber nature of vegetables controls blood sugar levels, prevents constipation, lowers the risk of digestive conditions, cardiovascular diseases, and blood cholesterol levels [2]. In fact, vegetables with the right proportion of antioxidants, minerals, and phytochemical help in keeping blood sugar in balance, create better energy in the body and build up the immune system (with the addition of fruits). Non-leafy vegetables like garlic and onions contain allicin, the anti-viral, antibacterial, and anti-fungal phytochemical that can act antibiotics [4]. The human-body need for vegetable cannot be overemphasized because vegetables are essential dietary requirements for a healthy living. However, huge post-harvest losses of vegetables are experienced by farmers and marketers due to the high perishability nature of fresh vegetables, poor handling, and inadequate storage facilities. FAO [5] reported that over $23 \%$ of most perishable fruits and vegetables are lost during their journey (harvesting, transportation, processing, and packaging) through the agricultural food chain due to spoilage, physiological decay, water loss, and mechanical damage. These losses have been estimated to be more than $50 \%$ in the tropics and sub-tropics. To reduce these losses and derive maximum utilization and economic gains from vegetables, adequate preservation by way of processing vegetables is required. Quality preservation, safety and enhanced long shelf life of vegetables are areas of interest in modern manufacturing. Cutting is one of the major operations required for the processing of vegetables. This unit operation is carried out via manual techniques. The output of the manual technique has been found to be low and wastes time due to the drudgery of the process. Shredding (slicing, cutting or dicing) of vegetables by using kitchen knife exposes human to the danger of knife cut.

Diverse works have been carried out on shredding process. For instance, Ndukwua and Onyenwigwe [6] worked on the development of a motorized parboiled cassava tuber shredding machine in 2013. Leo and Balogun [7] developed a functional multi-crop slicing machine while Raji and Igbeka [8] invented a pedal operated chipping and slicing machine for tubers. Food processor [9], vegetable shredder [10], and processing apparatus for leafy vegetables [11] have been developed over the years. Tony et al. [12] designed and developed an automated vegetable cutting machine; Frank [13] worked on blade assembly for paper 
shredder. Nithyananth et al. [14] and Joseph [15] designed waste shredding machines for wastes seize reduction, while Mandal [16] made available data required for design of shredder blades. Gear protection device of a paper shredder was developed by Frank [17]. The blade for the paper shredding cutting tool was designed and produced by Emily [18]. the rotational speed controlling the system for shredder motors was investigated by Hunag [19].

Despite the various existing vegetable shredding machines, none has been able to shred fluted pumpkin leaves effectively resulting from its tiny nature, plastic tendency, hence the concerns to study and improve on the already existing vegetable cutting machines, so as to shred the fluted pumpkin and other useful vegetable leaves efficiently becomes a necessity which can be achieved by precise machining of two rotor blades closely arranged.

Going by the general method of processing vegetables by slicing before preparation in that vegetable leaves by rapping together or clustering a number of leaves and placing them on a wooden slicing board and then cutting with a knife against the wooden slicing board, it was seen that this manual method is not hygienic, time wasting, tedious i.e. energy consuming and the risk associated with sustaining injuries during the operation makes it dangerous. The unhygienic nature of the manual method can be seen from the environmental where the slicing is done which may not be clean. While slicing, some vegetable can fall to this environment and by putting them back into the wooden slicing board from which they fell off is unhealthy. Also the clips from the wooden slicing board can be seen among sliced vegetable leaves due to continue or every day usage of the knife on the wooden slicing board. The dangerous aspect of this manual method can be seen from the use of knife and the wooden slicing board in the case of speedy slicing by some commercial vegetable sellers in attending to the pressing need of very many customers almost at the same time often results to injuries by the sharpened knife, therefore increasing the occurrence of accident which may result to infection.

Now, looking at the aforementioned drawbacks, the use of a vegetable shredding or slicing machine becomes a necessity for quick, efficient and hygienically processing of vegetables leaves. Also the freshness in food is highly guaranteed in that many homes will want to afford it because most often slice vegetables in the market before getting home which could affect the freshness. This research focuses on the design and fabrication of a vegetable shredding machine that is capable of hygienically processing a small to medium scale quantity of leafy vegetables at an optimized time (time saving and increased production).

\section{WORKING PRINCIPLE}

The machine consists essentially of two rotor blades which is enclosed in the shredding unit. The vegetable leaves are fed through the hopper (feeding Unit) into the machine for processing and the feeding is aided by gravity. The bottom end of the hopper connects to the shredding unit which encloses the two rotor blades. As the machine is powered by an electric motor, the gear driver on the electric motor transmit motion to the gear on the rotor blades (driven gear) through an idler gear, this enables the rotor blades to drag the vegetable leaves as a result of its opposite direction of rotation and with the assistance of the relative gear motion on the two rotor blades, shredding (cutting or sliding) of the vegetables is made possible. The machine is driven by a 1 HP electric motor at a speed of $1385 \mathrm{rpm}$. The speed of the motor is reduced by the gear system when the machine is in operation. It has good effect of shredding, long service life, reliable performance, very portable and able to add value for the people using it.

\section{RESEARCH METHOD}

The steps of the research are as follows:

1. Exploratory study of the various kinds of vegetable shredding machines

2. data analysis of the result of the exploratory study, and the comparison of those results with the results of a literature search, so as to design a vegetable shredding machine that is suitable for the conditions of small scale/ medium scale industries, measuring the capacity needed for the vegetable shredding machine to perform effectively and efficiently.

3. Design and fabricate a vegetable shredding machine according to the design

4. Test the performance of the vegetable shredding machine by combining the variables consisting of:

- Motor power required (W);

- Optimal rotor blades rotation (rpm),

- Capacity of the shredding results 
- Total volume required for effective shredding of the vegetables.

\section{DESIGN CALCULATIONS AND ANALYSIS}

Several factors were put into consideration in the design of the vegetable shredding machine. They include drudgery reduction, simplicity, capacity, strength of materials to be used for fabrication and flexibility of the machine. The hopper, rotary blades, power drive mechanism, shaft design, bearings, supporting frame and the capacity of the machine are the components of the machine designed for.

\subsection{Hopper}

It is made of stainless steel and has a trapezoidal shape connected to a shaped extension. The base of the hopper opens into this extension from the top so that feeding of the vegetable is aided by gravity. This was achieved through a proper choice of inclination of the hopper to the horizontal which was made greater than the angle of repose (angle $45^{0}$ was chosen). The volume to be occupied by the vegetable is taken as the volume of the hopper. This volume is achieved by analyzing the trapezoidal shape of the hopper as a truncated pyramid. The volume of the hopper (volume of frustum) is expressed as:

$v=v_{2}-v_{1}$

But

$$
\begin{gathered}
v_{2}=\frac{1}{3} \times B_{t} \times H \\
v_{1}=\frac{1}{3} \times B_{b} \times h
\end{gathered}
$$

Where: $v_{2}=$ volume of pyramid which the frustum forms part $v_{1}=$ volume of the pyramid removed, $B_{t}=$ base area at the top of the pyramid $\left(22800 \mathrm{~mm}^{2}\right), H=$ entire height of the pyramid $(317 \mathrm{~mm}), B_{b}=$ base area at the bottom of the truncated pyramid $\left(2240 \mathrm{~mm}^{2}\right)$ and $h=$ height of the pyramid removed $(117 \mathrm{~mm})$. by substituting values into equations (3), (2) and (1), we have that $v_{2}=2406920 \mathrm{~mm}^{3}, \quad v_{1}=87136 \mathrm{~mm}^{3}$ and $v=2319784 \mathrm{~mm}^{3}$ respectively.

According to [20], the density of a body is expressed as $\rho=\frac{m}{v}$

Where: $v$ is the volume of hopper which the vegetable will occupy in $\mathrm{mm}^{3}, m$ is the mass of vegetable that can be processed per batch in $\mathrm{kg}$ and $\rho$ is the density of vegetable. According to [21], the density of vegetable was taken to be the average density of cabbage that is $0.000034 \mathrm{~kg} / \mathrm{m}^{3}$. Conversely, the mass of vegetable to be processed per batch was computed to be $78.87 \mathrm{~kg}$ by substituting values into equation (4).

According to [22], $C=\frac{m}{t}$

Where: $C$ is the capacity of the machine in $\mathrm{kg} / \mathrm{hr}, m$ is the mass per batch of the vegetable $(78.87 \mathrm{~kg})$ and $t$ is the operating time per hour estimated via testing of the machine as $0.00839 \mathrm{hr}$. The capacity of the machine is computed to be $9400.48 \mathrm{~kg} / \mathrm{hr}$ using equation (5).

\subsection{Power Requirement}

According to [21], $F_{c}=m g$

Where: $F_{c}$ is the cutting force of the cutting blade $(\mathrm{N}), m$ is mass of vegetable per batch $(78.87 \mathrm{~kg})$ and $g$ is the acceleration due to gravity $\left(9.81 \mathrm{~m} / \mathrm{s}^{2}\right)$. The cutting force $\left(F_{c}\right)$ is estimated as $773.71 \mathrm{~N}$ by substituting values into equation (6).

According to [21], $T_{c}=F_{c} r$

Where: $T_{c}$ is the cutting torque in $\mathrm{Nm}, F_{c}$ is the cutting force $(773.71 \mathrm{~N})$ and $r$ is the radial arm of the cutting blade determined experimentally as $0.016 \mathrm{~m}$. conversely, The cutting torque $\left(T_{c}\right)$ is estimated to be $12.38 \mathrm{Nm}$ by substituting values into equation (7).

Similarly, according to [21], $P_{c}=\frac{2 \pi N T_{C}}{60}$ 
Where: $P_{c}$ is the power required to cut the vegetables in Watt, $N$ is the speed of the cutting blade estimated as (346.25rev/min) which is 0.25 of the speed of the electric motor (1385rev/min) selected and $T_{c}$ is the cutting torque (12.38Nm). by substituting value into equation (8), $P_{c}$ is estimated as 448.89 Watt. Thus, for a smooth operation of the machine 1 hp electric motor running at $1385 \mathrm{rev} / \mathrm{min}$ was selected.

\subsection{Gear Design}

Gears are used to transmit power or motion between an input and output shaft at a constant velocity ratio without any slippage.

The diameter of the spur gear shaft need to be computed following the procedure outlined by [21]. A single phase electric motor of $1 \mathrm{hp}$ was chosen for the drive mechanism. The electric motor selected delivers a speed of 1385rpm which was stepped down to the required speed (346.25rpm) by appropriate shredding gearing system. The diameter of the motor gear (driver gear) was taken to be $26 \mathrm{~mm}$. According to [21], the velocity ratio of gear is expressed mathematically as:

$$
V \cdot R=\frac{N_{1}}{N_{2}}=\frac{D_{2}}{D_{1}}=\frac{T_{2}}{T_{1}}
$$

Where: $N_{1}$ is speed of the driver gear $(1385 \mathrm{rpm}), N_{2}$ is speed of the driven gear $(346.25 \mathrm{rpm}), D_{1}$ is the diameter of the driver gear (26mm), $D_{2}$ is the diameter of the driven gear, $T_{2}$ is the number of teeth on the driven gear and $T_{1}$ is the number of teeth on the driver gear. $D_{2}$ is estimated as $104 \mathrm{~mm}$ by substituting the value into equation (9). In order to determine the number of gear teeth, the $14 \frac{1}{2}^{0}$ composite involute gear system was adopted for the design because it is stronger and has no interchangeability. The tooth profile has cycloidal curves at the top and bottom and involute curve at the middle [21]. The table below shows the standard proportions of the gear system adopted in module $(\mathrm{m})$

Table 1: Standard proportions of gear system adopted

\begin{tabular}{|l|l|c|}
\hline S/n & Particulars & $14 \frac{1}{2}^{0}$ composite of full dept involutes system (m) \\
\hline 1 & Addendum & 1 \\
\hline 2 & Dedendum & 1.25 \\
\hline 3 & Working depth. & 2 \\
\hline 4 & Minimum total depth. & 2.25 \\
\hline 5 & Tooth thickness & 1.5708 \\
\hline 6 & Minimum Clearance & 0.25 \\
\hline 7 & Fillet radius at root & 0.4 \\
\hline
\end{tabular}

There was a need for a provision of an idler (intermediate) gear based on the distance between the motor shaft and the first rotor shaft and also the orientation which is very essential in the machine during feeding process. The distance between motor shaft Centre and the first rotor Centre was considered to be $143 \mathrm{~mm}$. It is based on this distance and the speed reduction desired, that the gear pitch circle diameters for motor shaft and first rotor shaft were estimated to be $26 \mathrm{~mm}$ and $104 \mathrm{~mm}$ respectively while the intermediate gear was computed to have a pitch circle diameter of $78 \mathrm{~mm}$. According to [21], there are standard modules that are employed in cutting gears, the series are 1, 1.25, 1.5, 2, 2.5, 3, 4, 5, 6, 8, 10, 12, 16 and 20. A module of 2 was chosen for the gear cutter. The table below shows how the module affects the particulars of the gear system adopted.

Table 2: Chosen module cutter

\begin{tabular}{|l|l|l|l|l|}
\hline S/N & Particulars & Drive gear & Idler/ intermediate gear & Driven gear. \\
\hline 1 & Pitch circle diameter & $26 \mathrm{~mm}$ & $78 \mathrm{~mm}$ & $104 \mathrm{~mm}$ \\
\hline 2 & Addendum & $2 \mathrm{~mm}$ & $2 \mathrm{~mm}$ & $2 \mathrm{~mm}$ \\
\hline 3 & Dedendum & $2.5 \mathrm{~mm}$ & $2.5 \mathrm{~mm}$ & $2.5 \mathrm{~mm}$ \\
\hline 4 & Working depth. & $4 \mathrm{~mm}$ & $4 \mathrm{~mm}$ & $4 \mathrm{~mm}$ \\
\hline 5 & Minimum total depth. & $4.5 \mathrm{~mm}$ & $4.5 \mathrm{~mm}$ & $4.5 \mathrm{~mm}$ \\
\hline 6 & Tooth thickness & $3.14 \mathrm{~mm}$ & $3.14 \mathrm{~mm}$ & $3.14 \mathrm{~mm}$ \\
\hline 7 & Minimum Clearance & $0.5 \mathrm{~mm}$ & $0.5 \mathrm{~mm}$ & $0.5 \mathrm{~mm}$ \\
\hline 8 & Fillet radius at root & $0.8 \mathrm{~mm}$ & $0.8 \mathrm{~mm}$ & $0.8 \mathrm{~mm}$ \\
\hline
\end{tabular}


According to [21], the number of teeth per gear was obtained from the formula

$m=\frac{D}{T}$

Where: $m$ is the module (2), $D$ is the pitch circle diameter and $T$ is the number of teeth. Thus, for $D=26 \mathrm{~mm}, 78 \mathrm{~mm}$ and $104 \mathrm{~mm}$, the number of teeth are $T=13,39$ and 52 respectively. These are obtained by substituting the values of the respective diameter into equation (10).

Similarly, to obtain rotating motion and torque on the second rotor shaft and to obtain the relative speed on the rotors, two gears of different pitch circle diameters were employed to mesh and transmit the motion. The distance between the centre lines of the first and second rotor was estimated to be $32 \mathrm{~mm}$ for optimum shredding. Based on experiment, the appropriate speed ratio on the rotors was estimated to be in the ratio of $2: 1$ and as a result, the gear with pitch circle diameter of $21 \mathrm{~mm}$ and $43 \mathrm{~mm}$ and modulus 1.5 were machined. Thus, using equation (10), the number of teeth for the gears were computed to be 14 teeth and 29 teeth respectively.

\section{DESIGN FOR THE GEAR AND SHAFT}

The gears used for the shredding machine were designed for tangential, dynamic and static tooth loads respectively.

\subsection{First gear}

\subsubsection{Tangential tooth load}

According to Khurmi and Gupta [21], the tangential tooth load is expressed as:

$W_{T}=\frac{P}{V} \times C_{S}$

Where: $W_{T}=$ permissible tangential tooth load in Newton; $P=$ power transmitted $(448.89 \mathrm{~W}) ; V=$ pitch line velocity in $\mathrm{m} / \mathrm{s}$ and $C_{S}$ $=$ service factor (for $8-10$ hours per day, the service factor is 1 ). The pitch line velocity is computed from the expression given by (21) as:

$V=\frac{\pi N D}{60}$

Where $N=$ reduced speed of the motor $(346.25 \mathrm{rpm}) ; D=26 \mathrm{~mm}(0.026 \mathrm{~m})$. thus, by substituting value into equation (12), $V$ is estimated as $0.471 \mathrm{~m} / \mathrm{s}$. conversely, $W_{T}=953.06 \mathrm{~N}$ by substituting values into equation (11).

\subsubsection{Dynamic tooth load}

The dynamic tooth load of a gear according to [21] is expressed as:

$W_{D}=W_{T}+W_{I}$

Where $W_{D}=$ total dynamic load; $W_{T}=$ steady transmitted load (permissible tangential load and $W_{I}=$ increment load due to dynamic action. However, the increment load due to dynamic action is expressed according to [21] as

$W_{I}=\frac{21 v\left(b \cdot C+W_{T}\right)}{21 v+\sqrt{b . C+W_{T}}}$

Where:

$W_{I}=$ increment load due to dynamic action; $W_{T}=$ steady transmitted load $(953.06 \mathrm{~N}), b=$ face width of gears in mm which according to [21] is taken as $9.5 \mathrm{~m}$ and $m=2$, thus, $\mathrm{b}=19 \mathrm{~mm}$ and $C=$ deformation or dynamic factor (880N-mm). By substituting values into equation (14) and (13), we have that $W_{I}=1223.85 \mathrm{~N}$ and $W_{D}=2176.91 \mathrm{~N}$.

\subsubsection{Static Tooth Load}

According to Lewis formula given by [21], the static tooth load or beam strength of the tooth is expressed as: 
International Journal of Advances in Scientific Research and Engineering (ijasre), Vol 6 (4), April -2020

$W_{S}=\sigma_{e} \cdot b \cdot P_{c} \cdot y=\sigma_{e} \cdot b \cdot \pi m \cdot y$

Where: $W_{S}=$ static tooth load, $\sigma_{e}=$ flexural endurance limit or elastic limit stress $(252 \mathrm{MPa}), b=$ face with of the gear $(19 \mathrm{~mm}), m$ $=$ module (2) and $y=$ Lewis factor for $14 \frac{1}{2}^{0}$ involute teeth tooth form for the gear expressed by [21] as:

$y=0.124-\frac{0.684}{\text { no.of teeth }}$

Where the no. of teeth $=13$, thus, $y$ is estimated to be 0.0714 by substituting values into equation (16) while $W_{S}=2148.3 \mathrm{~N}$ by computing using equation (15).

\subsubsection{Design for shaft for the first gear}

Since the shaft is under the effect of torsion only, therefore we shall use the equation presented by [21] to determine the equivalent torque. The equivalent torque is expressed as,

$T_{e}=\sqrt{M^{2}+T^{2}}$

Where $M$ is the bending moment which is zero in this case and

$T$ is the twisting moment expressed as $W_{T} \times D_{g} / 2$

Where $D_{g}=26 \mathrm{~mm}$, thus, by substituting values into (18) and (17) respectively, we have that $T=12389.78 \mathrm{Nmm}$ and $T_{e}=$ $12389.78 \mathrm{Nmm}$

According to [21], the diameter of the gear shaft is determined using the following relation,

$T_{e}=\frac{\pi}{16} \times \tau \times d^{3}$

Where: $\tau$ is the shear stress for the steel material used for the gear shaft and according to ASME code for shaft with key way the value is $40 \mathrm{~N} / \mathrm{mm}^{2}, d$ is the diameter of the gear shaft estimated as $12 \mathrm{~mm}$ by substituting the values of $T_{e}$ and $\tau$ into equation (19).

\subsection{Second Gear}

\subsubsection{Tangential tooth load}

According to Khurmi and Gupta [21], the tangential tooth load is expressed as:

$$
W_{T}=\frac{P}{V} \times C_{S}
$$

Where: $W_{T}=$ permissible tangential tooth load in Newton; $P=$ power transmitted $(448.89 \mathrm{~W}) ; V=$ pitch line velocity in $\mathrm{m} / \mathrm{s}$ and $C_{S}$ $=$ service factor (for $8-10$ hours per day, the service factor is 1 ). The pitch line velocity is computed from the expression given by (21) as:

$V=\frac{\pi N D}{60}$

Where $N=$ reduced speed of the motor $(346.25 \mathrm{rpm}) ; D=104 \mathrm{~mm}(0.104 \mathrm{~m})$. thus, by substituting value into equation $(12), V$ is estimated as $1.885 \mathrm{~m} / \mathrm{s}$. conversely, $W_{T}=238.14 \mathrm{~N}$ by substituting values into equation (11).

\subsubsection{Dynamic tooth load}

The dynamic tooth load of a gear according to [21] is expressed as:

$W_{D}=W_{T}+W_{I}$

Where $W_{D}=$ total dynamic load; $W_{T}=$ steady transmitted load (permissible tangential load and $W_{I}=$ increment load due to dynamic action. However, the increment load due to dynamic action is expressed according to [21] as 
International Journal of Advances in Scientific Research and Engineering (ijasre), Vol 6 (4), April -2020

$W_{I}=\frac{21 v\left(b \cdot C+W_{T}\right)}{21 v+\sqrt{b . C+W_{T}}}$

Where:

$W_{I}=$ increment load due to dynamic action; $W_{T}=$ steady transmitted load $(238.14 N), b=$ face width of gears in mm which according to [21] is taken as $9.5 \mathrm{~m}$ and $m=2$, thus, $\mathrm{b}=19 \mathrm{~mm}$ and $C=$ deformation or dynamic factor (880N-mm). By substituting values into equation (14) and (13), we have that $W_{I}=3953.22 \mathrm{~N}$ and $W_{D}=4191.36 \mathrm{~N}$.

\subsubsection{Static Tooth Load}

According to Lewis formula given by [21], the static tooth load or beam strength of the tooth is expressed as:

$W_{S}=\sigma_{e} \cdot b \cdot P_{c} \cdot y=\sigma_{e} \cdot b \cdot \pi m \cdot y$

Where: $W_{S}=$ static tooth load, $\sigma_{e}=$ flexural endurance limit or elastic limit stress $(252 \mathrm{MPa}), b=$ face with of the gear $(19 \mathrm{~mm}), m$ $=$ module (2) and $y=$ Lewis factor for $14 \frac{1}{2}^{0}$ involute teeth tooth form for the gear expressed by [21] as:

$y=0.124-\frac{0.684}{\text { no.of teeth }}$

Where the no. of teeth $=52$, thus, $y$ is estimated to be 0.1108 by substituting values into equation $(16)$ while $W_{S}=3333.3 \mathrm{~N}$ by computing using equation (15).

\subsubsection{Design for shaft for the second gear}

Since the shaft is under the effect of torsion only, therefore we shall use the equation presented by [21] to determine the equivalent torque. The equivalent torque is expressed as,

$T_{e}=\sqrt{M^{2}+T^{2}}$

Where $M$ is the bending moment which is zero in this case and

$T$ is the twisting moment expressed as $W_{T} \times D_{g} / 2$

Where $D_{g}=104 \mathrm{~mm}$, thus, by substituting values into (18) and (17) respectively, we have that $T=12383.28 \mathrm{Nmm}$ and $T_{e}=$ $12383.28 \mathrm{Nmm}$

According to [21], the diameter of the gear shaft is determined using the following relation,

$T_{e}=\frac{\pi}{16} \times \tau \times d^{3}$

Where: $\tau$ is the shear stress for the steel material used for the gear shaft and according to ASME code for shaft with key way the value is $40 \mathrm{~N} / \mathrm{mm}^{2}, d$ is the diameter of the gear shaft estimated as $12 \mathrm{~mm}$ by substituting the values of $T_{e}$ and $\tau$ into equation (19).

\subsection{Third Gear}

\subsubsection{Tangential tooth load}

According to Khurmi and Gupta [21], the tangential tooth load is expressed as:

$W_{T}=\frac{P}{V} \times C_{S}$

Where: $W_{T}=$ permissible tangential tooth load in Newton; $P=$ power transmitted $(448.89 \mathrm{~W}) ; V=$ pitch line velocity in $\mathrm{m} / \mathrm{s}$ and $C_{S}$ $=$ service factor (for $8-10$ hours per day, the service factor is 1 ). The pitch line velocity is computed from the expression given by (21) as:

$V=\frac{\pi N D}{60}$ 
Where $N=$ reduced speed of the motor $(346.25 \mathrm{rpm}) ; D=78 \mathrm{~mm}(0.078 \mathrm{~m})$. thus, by substituting value into equation (12), $V$ is estimated as $1.414 \mathrm{~m} / \mathrm{s}$. conversely, $W_{T}=317.46 \mathrm{~N}$ by substituting values into equation (11).

\subsubsection{Dynamic tooth load}

The dynamic tooth load of a gear according to [21] is expressed as:

$W_{D}=W_{T}+W_{I}$

Where $W_{D}=$ total dynamic load; $W_{T}=$ steady transmitted load (permissible tangential load and $W_{I}=$ increment load due to dynamic action. However, the increment load due to dynamic action is expressed according to [21] as

$W_{I}=\frac{21 v\left(b \cdot C+W_{T}\right)}{21 v+\sqrt{b . C+W_{T}}}$

Where:

$W_{I}=$ increment load due to dynamic action; $W_{T}=$ steady transmitted load $(317.46 N), b=$ face width of gears in mm which according to [21] is taken as $9.5 \mathrm{~m}$ and $m=2$, thus, $\mathrm{b}=19 \mathrm{~mm}$ and $C=$ deformation or dynamic factor (880N-mm). By substituting values into equation (14) and (13), we have that $W_{I}=3157.57 \mathrm{~N}$ and $W_{D}=3475.03 \mathrm{~N}$.

\subsubsection{Static Tooth Load}

According to Lewis formula given by [21], the static tooth load or beam strength of the tooth is expressed as:

$W_{S}=\sigma_{e} \cdot b \cdot P_{c} \cdot y=\sigma_{e} \cdot b \cdot \pi m \cdot y$

Where: $W_{S}=$ static tooth load, $\sigma_{e}=$ flexural endurance limit or elastic limit stress $(252 \mathrm{MPa}), b=$ face with of the gear $(19 \mathrm{~mm}), m$ $=$ module (2) and $y=$ Lewis factor for $14 \frac{1}{2}^{0}$ involute teeth tooth form for the gear expressed by [21] as:

$y=0.124-\frac{0.684}{\text { no.of teeth }}$

Where the no. of teeth $=39$, thus, $y$ is estimated to be 0.106 by substituting values into equation $(16)$ while $W_{S}=3188.89 \mathrm{~N}$ by computing using equation (15).

\subsubsection{Design for shaft for the third gear}

Since the shaft is under the effect of torsion only, therefore we shall use the equation presented by [21] to determine the equivalent torque. The equivalent torque is expressed as,

$T_{e}=\sqrt{M^{2}+T^{2}}$

Where $M$ is the bending moment which is zero in this case and

$T$ is the twisting moment expressed as $W_{T} \times D_{g} / 2$

Where $D_{g}=78 \mathrm{~mm}$, thus, by substituting values into (18) and (17) respectively, we have that $T=12380.94 \mathrm{Nmm}$ and $T_{e}=$ $12380.94 \mathrm{Nmm}$

According to [21], the diameter of the gear shaft is determined using the following relation,

$T_{e}=\frac{\pi}{16} \times \tau \times d^{3}$

Where: $\tau$ is the shear stress for the steel material used for the gear shaft and according to ASME code for shaft with key way the value is $40 \mathrm{~N} / \mathrm{mm}^{2}, d$ is the diameter of the gear shaft estimated as $12 \mathrm{~mm}$ by substituting the values of $T_{e}$ and $\tau$ into equation (19). 
International Journal of Advances in Scientific Research and Engineering (ijasre), Vol 6 (4), April -2020

\section{DESCRIPTION OF COMPONENTS}

The vegetable shredding is made up of various components namely; the hopper (feeding chamber), cutting rotor blades, Bearings, Gears, AC electric motor, Collection chamber (delivery chamber), frame and casing.

6.1 The Hopper: It is made of grade stainless steel. It has a trapezoidal shape through which the vegetable leaves are fed into the machine for shredding to take place.

6.2 The Cutting Rotor blades: The cutting rotor blades are precisely machined on the two rotor shafts closely arranged to the lowest degree of tolerance so that any thickness of vegetable leaves can be shredded. The cutting blades are made of hardened stainless steel material. Shredding occurs when the machine is powered and the blade is rotated by the rotational movement of the electric motor.

6.3 Bearing: The bearing support the rotor blade on both ends. Apart from supporting the rotor blades, it aligns the rotation of the rotor blades. i.e. making sure that there is no wobbling on the two oppositely rotating rotor blades. The bearing type used in the fabrication of this machine is the trust bearing with a stopper machined on the bearing housing to arrest any form of linear movement of the two rotor blades.

6.4 Gears: The transmission of power from the electric motor to the rotor blades are made possible by the gear on the electric motor (driver gear) connected to that on the rotor blades (driven gear) via an idler gear. Gears are used to either increase or decrease the speed depending on the designer's choice.

6.5 AC electric motor: The A.C electric motor is used run the cutting blade. Since the two rotor blades are rotating in opposite direction, vegetable leaves packed full into the hopper is dragged into the cutting chamber and shredding is done as a result of relative gear motion on the two rotor blades. The problem of using an electric motor for the feeding system is greatly eliminated.

6.6 Collection Chamber: The collection chamber also referred to as the delivery chamber is made of good grade stainless steel. Its primary function is to deliver already sliced vegetable leaves to a location it can be collected easily.

6.7 The Frame: This serves as the base upon which all other components are placed and housed. For this reason, the thickness of the frame is such that it is able to withstand vibrations and bending forces.

6.8 The Casing: The casing serves as cover for the entire machine components. The material is made of stainless steel. This is as a result of its corrosion resistant ability as the machine is most likely to be subjected to use in environments that is not corrosion friendly. 


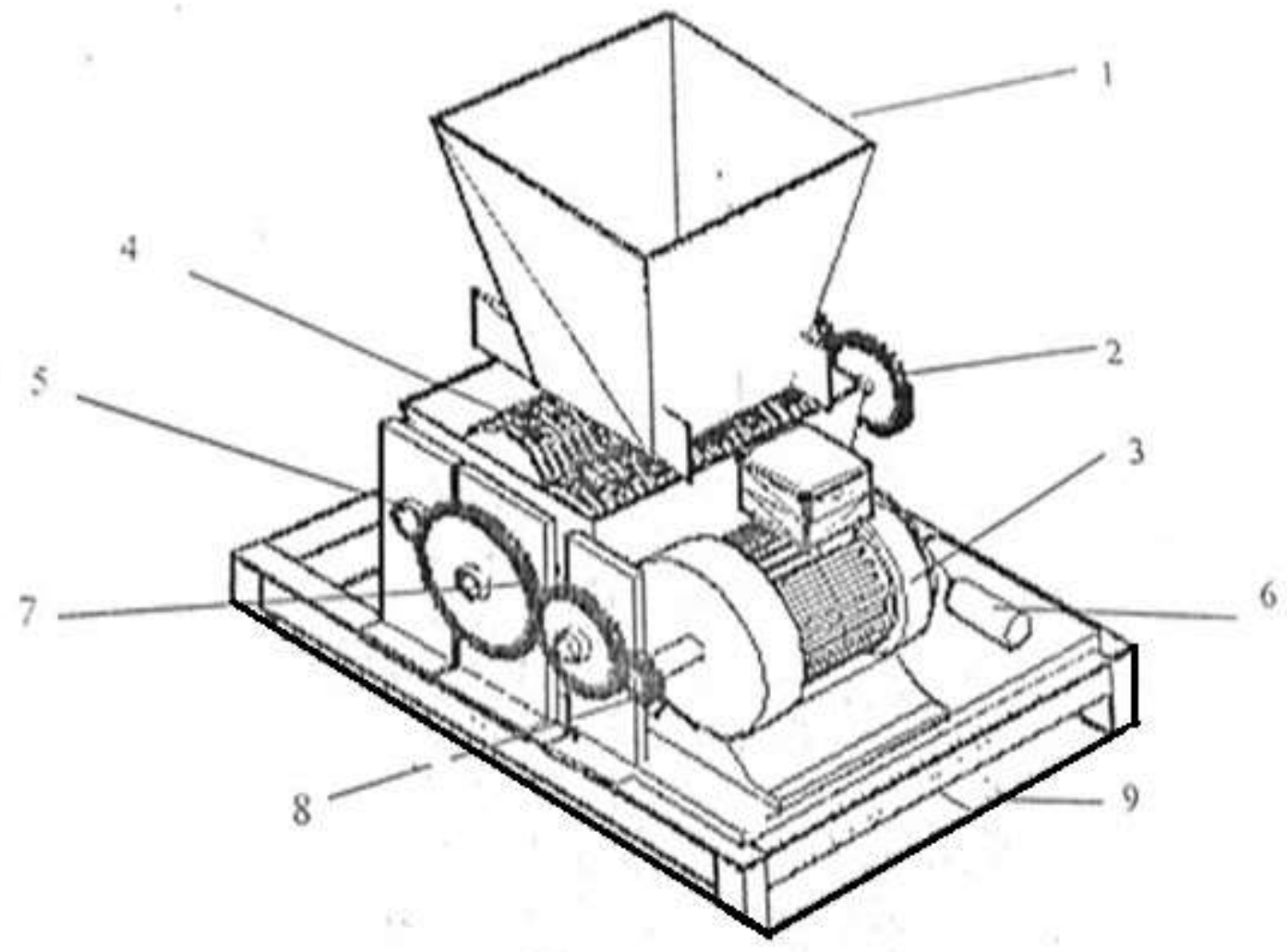

Fig.1: Isometric view of the machine

Table 3 : Part list of the various components of the machine

\begin{tabular}{|l|l|}
\hline S/N & MEMBER NAMES \\
\hline 1 & Hopper \\
\hline 2 & Driver Gear \\
\hline 3 & Electric Motor \\
\hline 4 & Cutting Rotor blades \\
\hline 5 & Spur Gear (Driven) \\
\hline 6 & Solenoid \\
\hline 7 & Spur Gear (Driven) \\
\hline 8 & Motor gear. \\
\hline 9 & Collecting chambers \\
\hline
\end{tabular}

\section{PERFORMANCE TEST OF THE MACHINE}

In realizing the aim of this research work, the performance test was carried out after machine parts have been assembled in the department of Mechanical Engineering technology, National Institute of Construction Technology and Management (NICTM), Uromi, Edo State, Nigeria. The machine was started and five samples of equal mass of pumpkin vegetable leaves were fed through the hopper, each time. A stop watch was used to monitor the time taken for the vegetable to be shredded per batch. A 1 horse power electric motor with a speed of $1385 \mathrm{rpm}$ was used as prime mover. 
International Journal of Advances in Scientific Research and Engineering (ijasre), Vol 6 (4), April -2020

\section{TESTING OF THE MACHINE}

Five tests were carried out. A total mass of $78.87 \mathrm{~kg}$ of vegetables were fed through the hopper when the machine was in operation and the time for proper shredding was recorded.

Table 4: Experimental test result

\begin{tabular}{|l|l|l|l|}
\hline S/n & $\begin{array}{l}\text { Mass of vegetables fed } \\
\text { into the machine }(\mathbf{k g})\end{array}$ & $\begin{array}{l}\text { Mass of vegetables not } \\
\text { properly shredded }(\mathbf{k g})\end{array}$ & $\begin{array}{l}\text { Time taken for proper shredding of } \\
\text { vegetables (seconds) }\end{array}$ \\
\hline 1 & 78.87 & 8.46 & 32 \\
\hline 2 & 78.87 & 8.35 & 29 \\
\hline 3 & 78.87 & 8.43 & 30 \\
\hline 4 & 78.87 & 8.40 & 31 \\
\hline 5 & 78.87 & 8.38 & 29 \\
\hline Average & $\mathbf{7 8 . 8 7}$ & $\mathbf{8 . 4 0}$ & $\mathbf{3 0 . 2}$ \\
\hline
\end{tabular}

\section{EFFICIENCY OF THE MACHINE}

From the five tests carried out. A total mass of $78.87 \mathrm{~kg}$ of pumpkin vegetables were taken and fed through the hopper when the machine was in operation. The mass of pumpkin vegetables not properly shredded were separated and weighed and their average taken. The result expected is as follows:

Average Mass of pumpkin fed into the machine $=78.87 \mathrm{~kg}$

Average Mass of pumpkin not properly shredded $=8.40 \mathrm{~kg}$

The mass output $=($ average mass of pumpkin fed into the machine - average mass of pumpkin not properly shredded $)=78.87-$ $8.40=70.47 \mathrm{~kg}$

Efficiency $=($ Output/ Input $) \times 100 \%=(70.47 / 78.87) \times 100 \%=89.35 \%$

\section{RESULTS AND DISCUSSION}

The results of the performance test show that the machine performed excellently well with an average shredding efficiency of $89.35 \%$, shredding time of 30.2 seconds and throughput capacity of $9400.48 \mathrm{~kg} / \mathrm{h}$.

\section{CONCLUSION}

A vegetable shredding machine was designed, fabricated and performance evaluation successfully carried out. The test result revealed that the machine has a shredding efficiency of $89.35 \%$ and a performance capacity of $9400 \mathrm{~kg} / \mathrm{h}$. the machine has the capability of shredding various kinds of vegetables at the shortest possible time. The machine is made up of simple components that can be easily assembled and was made from locally available materials in order to minimize the cost of production. Local experts can maintain and operate the machine with little or no training. It is anticipated that the machine when commercialized will meet the need of domestic and commercial users. 


\section{REFERENCES}

[1]. International Agency for research on cancer, "Handbooks of cancer prevention-fruits and vegetables", Lyon (France): IARC PRESS,2003.

[2]. N.M. Lewis, J. A. Albrecht, M. I. Schnepf, F. L. Hamouz, and J. A. Driskel, "Vegetable choices and cooking methods of Nebraskans". Journal of Economics Rise, 1994, Vol. 22, pp. 286-295

[3]. I. Castro- Ibanez, M.I. Gil, A. Allende, "Ready-to-eat vegetables: Current problems and potential solutions to reduce microbial risk in the production chain". LWT - Food Science and Technology, 2017, 85, pp. 284-292.

[4]. O. Jane, "Benefits of a variety of fruits and vegetables", URL: WWW.naturalchoicesforyou.com, 2005. Accessed on $18^{\text {th }}$ October, 2019

[5]. FAO, "Fruit and fruits processing. FAO Agricultural Services Bulletin No. 119”, Food and Agricultural Organization of the United Nations, Rome, Italy, 1995.

[6]. M.C. Ndukwua, and D. Onyenwigwe, "Development of a motorized parboiled cassava tuber shredding machine", Nigerian Journal of Technology (NIJOTECH), 2013, Vol. 32, No. 1, pp.1-6.

[7]. A. Leo, and A. Balogun, "Design and Performance Evaluation of a Multi-Crop Slicing Machine", $5^{\text {th }}$ CIGR Section International Symposium on Food Processing, Potsderm Germany, 2009.

[8]. O. A. Raji, and J. C. Igbeka, “Peedal Operated Chipping and Slicing Machine for Tubers”, Journal of Agricultural and Engineering Technology, 1994, pp. 90-99.

[9]. W. H. Lin, "Food processor". US patent grant no US5156084A,1992

[10]. Z. Karl, "Vegetable shredder". US patent grant no US2782826A, 1954

[11]. W. M. Hofmeister, "Method and apparatus for processing leafy vegetables". US patent Grant no US5727690A, 1995

[12]. A. Tony, A. Muthu, and K.S. SreNandha, "Design and development of automated vegetable cutting machine", $5^{\text {th }}$ International \& $26^{\text {th }}$ All India Manufacturing Technology, Design and research. Conference (AIMTDR 2014) December $12^{\text {th }}-14^{\text {th }}, 2014$, IIT Guwahati, Assam, India

[13]. C. Frank, "Blade Assembly for Paper Shredder” US6089482, BO2C18/06, BO2C18/18, 2000.

[14]. S. Nithyananth, N. S Matthew, S. L. Suraj,” Design of Waste Shredder”, ISSN:2248-9622, 2014, Vol.4, Issue 3, pp. 487-491

[15]. Y.K, Joseph, "Paper Shredding Device”, US639039BI, 2002.

[16]. D.P. Mandal, "Design Data Handbook for Mechanical Engineering” $2^{\text {nd }}$ Ed. Sanjeev Kuma Kataria, Delhi, 2013, pp. 20-26.

[17]. C. Frank Taipei, “Gear Protection Device of a Paper” 6325309BI, 2001.

[18]. L. Emily, T. Shiepei, "Blade for paper Shredder Cutting tool”, 7328867BI., 2008.

[19]. S. Hunag, S. Chung, "Rotation Speed Controlling System for Shredder motor”, 8000888262, 2011.

[20]. S. Hunag, S. Chung, "Elliptical Acetabuli for Blade Shredder”, 6981667B2, App. No. 10/682198, 2006.

[21]. R.S khurmi and J. K. Gupta, “A Textbook of Machine Design (S.I Units)”, Published by Eurasia Publishing House (PVT) Ltd, Ram Nagar, New Delhi, 2005. 